\title{
Microstructures of mantle peridotites and their implications on seismic anisotropy around Mt. Melbourne, northern Victoria Land, Antarctica
}

\author{
DAEYEONG KIM ${ }^{1}$, MunJAE PARK ${ }^{2}$, SUNG-HyUn PARK ${ }^{1}$
}

${ }^{1}$ Division of Polar Earth-System Sciences, Korea Polar Research Institute, South Korea

${ }^{2}$ Department of Geology, Korea University, South Korea

Exposed peridotites are usually regarded as window into physical and chemical properties of mantle, that help to explain present geophysical observations. We present microstructural analyses on six mantle xenoliths around Mt. Melbourne to delineate prossible explanation on widespread NE-SW-trending S-wave splitting developed in northern Victoria Land, Antarctica. Equilibrium temperatures are estimated as $890-920{ }^{\circ} \mathrm{C}$ by Ca-in-opx thermometer. The analyzed samples do not contain any structural indicators, therefore the [100] and [010] are rotated to vertical and horizontal directions, respectively. The shape factor, $K$, calculated from eigenvalues indicates clustered [100] and girdled/clustered [010], indicating D- or A-type olivine. Calculated seismic properties defined that the analyzed samples contain D- or A-type olivine by Fabric-Index Angle (FIA) method. Olivine in the analyzed samples do not show any signal of water content by Fourier-transform infrared spectroscopy (FTIR) analysis. Therefore the analyzed samples include D- or A-type olivine. The strongest seismic anisotropy from this study are calculated as $6.47 \%$, therefore it could fully generate the observed delay time of $0.9-1.3 \mathrm{~s}$ with an assumption of olivine [100] aligned to direction of the fast $\mathrm{S}$-wave splitting. Our results therefore indicate that the observed fast $\mathrm{S}$-wave splitting in northern Victoria Land could be explained by olivine in lithosperic mantle. Because the study area is located close to the Terror Rift area that could generate additional effects on S-wave splitting, therefore additional studies on mantle xenoliths in other localities of northern Victoria Land need to be explored. 